\title{
Clinical and Radiographic Assessment of Cases Referred to Endodontic Surgery
}

\section{Klinička i radiološka procjena pacijenata upućenih na endodontsku kirurgiju}

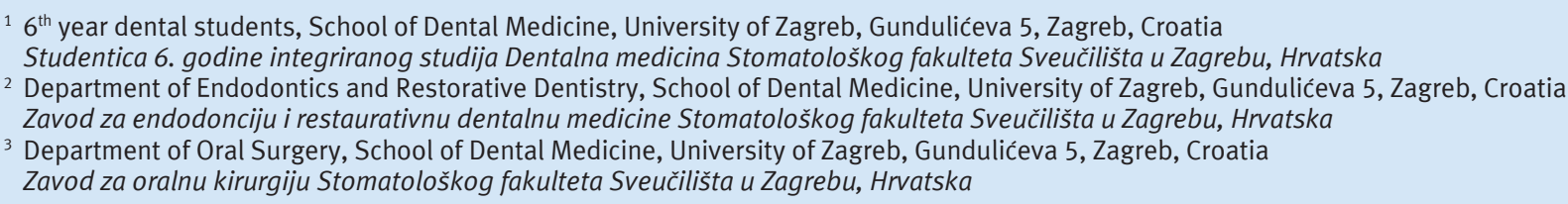

${ }^{1} 6^{\text {th }}$ year dental students, School of Dental Medicine, University of Zagreb, Gundulićeva 5, Zagreb, Croatia Studentica 6. godine integriranog studija Dentalna medicina Stomatološkog fakulteta Sveučilišta u Zagrebu, Hrvatska

2 Department of Endodontics and Restorative Dentistry, School of Dental Medicine, University of Zagreb, Gundulićeva 5, Zagreb, Croatia Zavod za endodonciju i restaurativnu dentalnu medicine Stomatološkog fakulteta Sveučilišta u Zagrebu, Hrvatska

${ }^{3}$ Department of Oral Surgery, School of Dental Medicine, University of Zagreb, Gundulićeva 5, Zagreb, Croatia Zavod za oralnu kirurgiju Stomatološkog fakulteta Sveučilišta u Zagrebu, Hrvatska

Received: December 27, 2018

Accepted: May 6, 2019

Address for correspondence

Ana Ivanišević Malčić

University of Zagreb School of Dental Medicine

Gundulićeva 5, 10000 Zagreb, Croatia Phone: +385989872905

Fax: +38514802159

aivanisevic@sfzg.hr

Key words

Decision Making; Dental Radiography; Endodontics; Endodontic Surgery; retreatment

\section{Introduction}

The purpose of endodontic treatment is to preserve the function of a tooth with pathologically altered pulp, without harming patients' general health. According to the $E u$ ropean Society of Endodontology (ESE) and American Association of Endodontists (AAE) guidelines, the standard procedure includes cleaning, shaping, disinfection and sealing the root canals of the treated tooth $(1,2)$. The treatment is considered successful when clinical symptoms of periapical disease are absent and radiographic analysis confirms the healing of a periapical lesion $(3,4)$.

According to the literature, $14-16 \%$ of primary endodontic treatments result in failure (5). If radiographic and clinical findings indicate failure, three therapeutic options should be considered: non-surgical retreatment, endodontic surgery (including root-end resection and retrograde cavity filling) or tooth extraction $(1,6)$. The most frequent cause of failure is persistent infection in the root canal system and/or in periradicular area $(7,8)$. Other possible reasons include periradicular true cyst, accumulation of endogenous cholesterol crystals

\section{Uvod}

Svrha endodontskog postupka jest očuvati funkciju zuba s patološki promijenjenom pulpom, a da se ne ugrozi pacijentovo opće zdravlje. Prema preporukama Europskoga endodontskog društva (engl. European Society of Endodontology - ESE) i Američke endodontske udruge (engl. American Association of Endodontists - AAE) standardni endodontski postupak uključuje čišćenje, širenje, dezinfekciju i punjenje korijenskih kanala $(1,2)$. Postupak se smatra uspješnim ako nema kliničkih simptoma periapikalne bolesti i kada radiološka analiza potvrđuje cijeljenje periapikalne lezije $(3,4)$.

Prema literaturi, od 14 do $16 \%$ primarnih endodontskih liječenja rezultira neuspjehom (5). Ako klinički nalaz i radiogram upućuju na neuspjeh, treba razmotriti tri terapijske mogućnosti - konzervativnu reviziju liječenja, endodontsku kirurgiju (uključujući resekciju vrška korijena i retrogradno punjenje) ili ekstrakciju zuba $(1,6)$. Najčešći uzrok za neuspjeh je trajna, perzistentna infekcija u sustavu korijenskih kanala i/ili u periradikularnom području $(7,8)$. Ostali mogući razlozi uključuju periradikularne prave ciste, akumula- 
in periapical tissue and foreign body reaction due to a root canal overfilling or cellulose-containing materials extruded during treatment $(7,9)$. When there is residual intraradicular infection, procedural mistakes such as short filling or overfilling, perforations of root canal wall and separated instrument could lead to failure $(8,10)$.

In the endodontic surgery procedure root tip is surgically removed together with the inflammatory process around it and retrograde cavity prepared and filled $(1,2)$. Endodontic surgery is indicated when periapical lesions persist and root canal system cannot be adequately cleaned and sealed due to developmental anomalies or iatrogenic causes or when the retreatment would compromise the tooth, e.g. the removal of the intracanal post. Furthermore, endodontic surgery needs to be performed if there is a suspicion of perforation or fracture in the root's apical third, when histopathological analysis is required and when retreatment is not possible due to the patient related reasons $(1,2,11)$. Cohn et al. (12) reported that the success rate of surgical endodontics was $64 \%$, which is considerably lower than the reported success rate of retreatments $(80 \%)(13)$. Also, undesirable consequences of this surgical procedure are gingival recessions, scars and reduced resistance to occlusal forces and periodontal diseases due to root shortening $(14,15)$. It is, therefore, crucial that the indications for endodontic surgery are met and that each case is individually assessed $(14,15,16)$. In the cases where neither retreatment nor endodontic surgery would enable inflammation regression and healing, tooth extraction is the treatment of choice (1).

It has been shown that the unsatisfactory quality of primary root canal fillings with inadequate length and homogeneity of the filling often leads to the development of a periapical process (17). An insufficient awareness of the etiology of persistent endodontic diseases and treatment possibilities leads to the increased referral to endodontic surgery (18).

According to the available literature, firm guidelines for failed root canal treatment seem to lack, and information about treatment decisions (orthograde retreatment vs. surgical treatment vs. extraction- implants) is modest $(12,18)$. The aim of this research was to determine the connection between the quality of root canal filling, symptoms, status of the tooth and surrounding tissues (clinical and radiographic) and treatment decision. The hypothesis was that endodontic surgery was the treatment of choice in the majority of the referred cases.

\section{Material and methods}

The study was conducted in surgical infirmaries and operating rooms at the Department of Oral Surgery, School of Dental Medicine, University of Zagreb and the Clinical Department of Oral Surgery, Clinical Hospital Dubrava, Zagreb from January to April 2017. The research has been conducted in accordance with the World Medical Association Declaration of Helsinki, and The Ethics Committee of the School of Dental Medicine, University of Zagreb approved the research and the consent procedure. The written consent was obtained from all the participants who were older that 18 , and from the parents of the participants that were under 18 years of age. ciju endogenih kolesterolskih kristala u periapikalnom tkivu i reakciju na strano tijelo zbog prepunjenja ili ekstruzije celuloznih materijala u periapeks tijekom liječenja $(7,9)$. Kada postoji rezidualna intraradikularna infekcija, proceduralne pogreške, poput kratkog punjenja ili prepunjenja perforacije korijena i separacije instrumenta, mogu rezultirati neuspjehom $(8,10)$.

U slučaju endodontsko-kirurškog zahvata, vršak korijena kirurški se uklanja (apikotomira) zajedno s upalnim područjem oko njega te se preparira i puni retrogradni kavitet $(1,2)$. Endodontska kirurgija indicirana je kada periapikalne lezije perzistiraju, a sustav korijenskih kanala ne može se adekvatno očistiti i zabrtviti zbog razvojnih anomalija ili ijatrogenih uzroka ili u slučaju da ortogradna revizija ugrožava zub, na primjer, kada je potrebno ukloniti intrakanalnu nadogradnju. Dodajmo da endodontsko-kirurški zahvat treba obaviti ako se sumnja da je apikalna trećina korijena perforirana ili frakturirana, kada je potrebna patohistološka analiza te kada revizija nije moguća zbog razloga vezanih za pacijenta $(1,2$, 11). Cohn i suradnici (12) istaknuli su da je postotak uspješnosti endodontske kirurgije $64 \%$, što je značajno manje od postotka uspješnosti revizije liječenja (80 \%) (13). Nadalje, nepoželjne posljedice ovoga kirurškog postupka su gingivna recesija, ožiljci, smanjena otpornost na okluzalne sile i parodontne bolesti zbog skraćenog korijena $(14,15)$. Zato je vrlo važno uzeti u obzir indikacije za endoodntsku kirurgiju i procijeniti individualno svaki slučaj $(14,15,16)$. U slučaju kada ni revizija, ni endodontska kirurgija ne mogu spriječiti regresiju upale i cijeljenje, ekstrakcija zuba je postupak izbora (1).

Pokazalo se da punjenja korijenskih kanala neadekvatne dužine i homogenosti često završavaju pojavom periapikalnih procesa (17). Nedovoljna svijest o etiologiji perzistentne endodontske bolesti i mogućnosti liječenja, uzrok je povećanog postotka upućivanja pacijenata na endodontsko-kirurški zahvat (18).

Prema dostupnoj literaturi, čvrste preporuke za neuspješno endodontsko liječenje ne postoje, a skromne su informacije i o terapijskim odlukama (ortogradna revizija liječenja vs. kirurška terapija vs. ekstrakcija - implantati) $(12,18)$. Svrha ovog istraživanja bila je povezati kvalitetu punjenja korijenskog kanala, simptome, status zuba i okolnih tkiva (klinički i radiološki) s odlukom o terapijskom postupku. Hipoteza je glasila da je za većinu upućenih pacijenata endodontsko-kirurški postupak bio terapijski postupak izbora.

\section{Materijali i metode}

Istraživanje je provedeno u kirurškim ambulantama $\mathrm{Za}-$ voda za oralnu kirurgiju Stomatološkog fakulteta Sveučilišta u Zagrebu i Kliničkog odjela za oralnu kirurgiju Kliničke bolnice Dubrava u Zagrebu, od siječnja do travnja 2017. Obavljeno je u skladu s Helsinškom deklaracijom Svjetske medicinske udruge, a odobrilo ga je Etičko povjerenstvo Stomatološkog fakulteta Sveučilišta u Zagrebu. Svi pacijenti stariji od 18 godina te roditelji onih mladih od 18 godina, potpisali su informirani pristanak.

Prije istraživanja dvije su istraživačice (B. B. i J. B.) za procjenu uskladile kliničke i radiološke dijagnoze. Kriteriji 
Prior to the research, two researchers (BB and JB) were calibrated for estimating clinical and radiographic diagnosis. The criteria for the assessment of clinical and radiographic findings were harmonized by analysing 51 digital retroalveolar and panoramic radiographs from the School of Dental Medicine, University of Zagreb database, recorded using Minray (for intraoral) and Cranex 3D Ceph (for orthopantomograms) X- ray machines and Scanora software (Soredex, Tuusula, Finland). The analyses were compared, and high degree of congruence was noticed. The results which did not match were processed and discussed and a 100\% congruence was achieved.

Eighty-six patients referred to endodontic surgery participated in the study. Only the patients who signed the informed consent were included, and their anonymity was guaranteed. Clinical and radiographic finding, the decision of an oral surgery specialist about further procedure and intraoperative findings were recorded for each case. Dental history included data about previous procedures on the tooth and pain assessment. Clinical examination included tooth and soft tissue inspection. A radiographic analysis was conducted on panoramic $(n=2)$ and intraoral $(n=101)$ radiographs which included the assessment of homogeneity and filling length with respect to the radiographic apex, the presence of a separated instrument in root canal and the presence of perforation (19), the length and type of posts and the size of periapical transparency. When endodontic surgery was indicated, intraoperative findings of bone fenestration, dehiscence or vertical fracture of a tooth was recorded. The radiographs were made and analyzed using Minray and Cranex 3D Ceph machine (Soredex, Tuusula, Finland) and Scanora software (Soredex, Tuusula, Finland).

Cases referred to endodontic surgery for the first time and cases referred to repeated endodontic surgery were joined in one sample. When analyzing the data of patients that had multiple teeth referred for apicoectomy, each tooth was observed and anlyzed individually.

The relationships between radiographically estimated quality of root canal filling (according to homogeneity and filling length), clinical and radiographic variables, variables from dental history and decision about the procedure were statistically analyzed. The $\chi 2$-test was used for the analysis of discrete variables and $\mathrm{t}$-test for continuous variables $(\mathrm{p}<$ 0.05 ). The analysis was done using SAS statistical package on Windows platform.

\section{Results}

Out of 86 patients that participated in the study, 59.5\% were female and $40.5 \%$ of them were male. More cases were evaluated in the operating room than in the surgical infirmary (3.8:1). There were no statistical differences between males and females for any variable ( $p>0.05)$. Patients' average age was 44.4 years (14-81 years). Out of 106 analyzed teeth, $97.2 \%$ were treated by a general practice dentist. Endodontic retreatment before referring to endodontic surgery was performed in $20.6 \%$ of cases. The most common treatment selection was endodontic surgery $(90.1 \%)$, while retreatment za procjenu kliničkoga i radiološkog nalaza usklađeni su analiziranjem 51 digitalne retroalveolarne i panoramske snimke iz baze snimaka Stomatološkog fakulteta Sveučilišta u Zagrebu učinjenih uređajima Minray (za intraoralne) i Cranex 3D Ceph (za ortopantomograme) te obrađenih softverom Scanora (Soredex, Tuusula, Finska). Analize su uspoređene te je postignut visok stupanj podudarnosti. Rezultati koji se nisu podudarali analizirani su i o njima se raspravljalo te je postignuta podudarnost u $100 \%$ slučajeva.

U istraživanju je sudjelovalo 86 pacijenata upućenih na endodontsko-kirurški zahvat (apikotomiju). Samo su oni koji su potpisali informirani pristanak sudjelovali u istraživanju, a anonimnost je bila zajamčena. Klinički i radiološki nalaz, odluka specijalista oralne kirurgije o daljnjem postupku te intraoperativni nalaz, zabilježeni su za pojedini slučaj. Dentalna anamneza uključivala je podatke o ranijim postupcima na zubu i procjenu boli. Klinički pregled uključivao je inspekciju zuba i okolnih mekih tkiva. Radiološka analiza učinjena je na ortopantomogramima $(n=2)$ i intraoralnim radiogramima $(\mathrm{n}=101)$ te je obuhvaćala procjenu homogenosti i duljine punjenja prema radiološkom apeksu, prisutnost separiranog instrumenta u korijenskom kanalu i perforaciju korijena (19), duljinu i vrstu nadogradnje te veličinu periapikalne transparencije. Ako je bio indiciran endodontsko-kirurško zahvat, zabilježen je intraoperativni nalaz fenestracije kosti, dehiscijencija ili vertikalna fraktura. Radiogrami su snimljeni i analizirani uređajima Minray i Cranex 3D Ceph (Soredex, Tuusula, Finska ) te softverom Scanora (Soredex, Tuusula, Finska).

Slučajevi koji su prvi put upućeni na endodontsko-kirurški zahvat te oni upućivani više puta, spojeni su u jedan uzorak. Kod pacijenta upućenih zbog dvaju ili više zuba, svaki je zub promatran $\mathrm{i}$ analiziran posebno.

Statistički su analizirani odnosi između radiološki procijenjene kvalitete punjenja korijenskog kanala (prema homogenosti i duljini punjenja), kliničkih i radioloških varijabli, varijabli iz dentalne anamneze i odluke o postupku. $\chi 2$-test korišten je $\mathrm{u}$ analizi diskretnih varijabli, a t-test kontinuiranih varijabli $(\mathrm{p}<0,05)$. Analiza je obavljena u statističkom paketu SAS na platformi Windowsa.

\section{Rezultati}

Među 86 pacijenata koji su sudjelovali u istraživanju, $59,5 \%$ bile su žene, a 40,5\% muškarci. Više slučajeva analizirano je u operacijskoj dvorani, negoli u ambulanti $(3,8$ : 1). Nije bilo statistički značajnih razlika među spolovima ni za jednu varijablu $(\mathrm{p}>0,05)$. Prosječna dob pacijenta bila je 44,4 godine (14 - 81 godinu). Od 106 analiziranih zuba, $97,2 \%$ tretirao je primarni liječnik dentalne medicine. Revizija endodontskog liječenja prije dolaska na endodontsku kirurgiju učinjena je u 20,6 \% slučajeva. Najčešći odabrani postupak bio je endodontsko-kirurški $(90,1 \%)$, a revizija $(5,4$ 
Table 1 Numbers and percentages of particular clinical and radiological findings recorded in 109 teeth of 86 patients referred to endodontic surgery.

Tablica 1. Brojevi i postotci specifičnoga kliničkog i radiološkog nalaza na uzorku od 109 zuba i 86 pacijenata upućenih na endodontsku kirurgiju

\section{Tooth}

11 -maxillary right central incisor

12-maxillary right lateral incisor

13- maxillary right canine

14-maxillary right second premolar

21-maxillary left central incisor

22- maxilary left lateral incisor

23- maxillary left canine

24- maxillary left first premolar

25- maxillary left second premolar

26- maxillary left first molar

32- mandibular left lateral incisor

33- mandibular left canine

34- mandibular left first premolar

35- mandibular left second premolar

41- mandibular right central incisor

42- mandibular right lateral incisor

43- mandibular right canine

44- mandibular right first premolar

Prosthetically reconstructed tooth

Yes

No

Single crown

Yes

No

Bridge carrier

Yes

No

Number of previous treatments

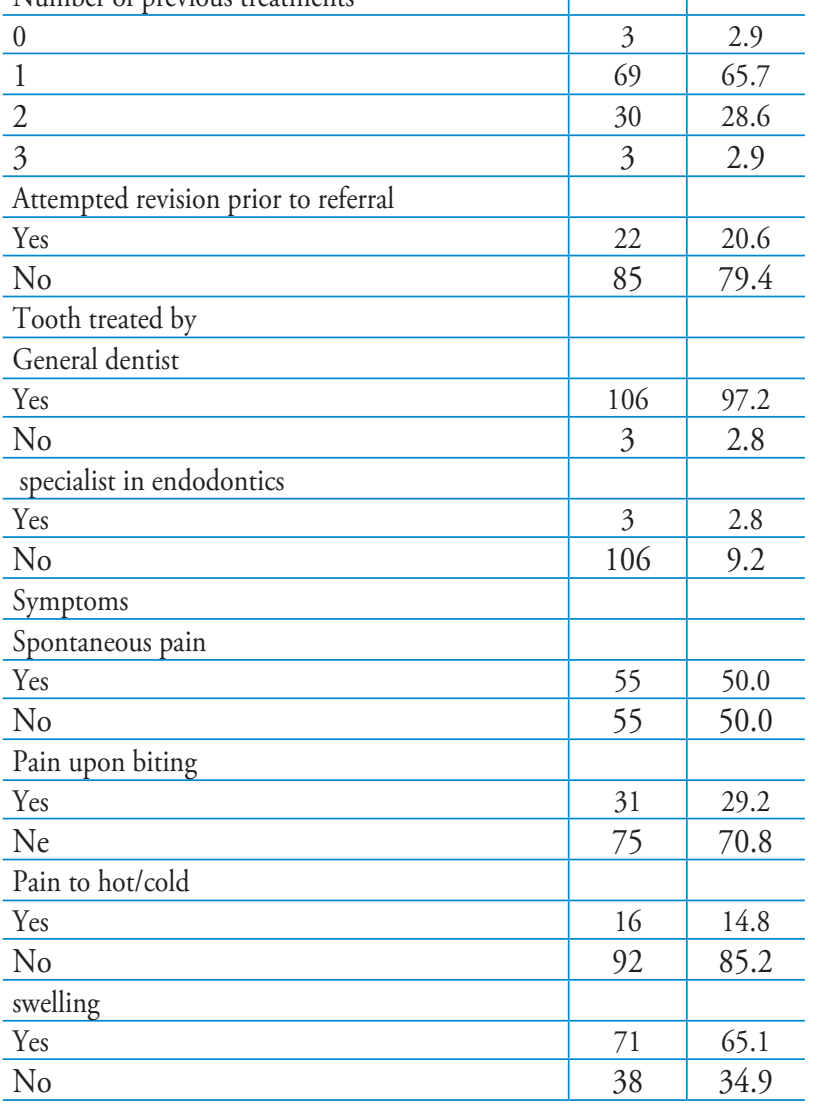

\begin{tabular}{l|l}
13 & 11.9 \\
\hline 18 & 16.5 \\
\hline 11 & 10.1 \\
\hline
\end{tabular}

\begin{tabular}{c|c}
\hline 2 & 1.8 \\
\hline 20 & 18.3
\end{tabular}

\begin{tabular}{l|l}
21 & 19.3 \\
\hline
\end{tabular}

\begin{tabular}{l|l}
4 & 3.7
\end{tabular}

\begin{tabular}{l|l}
5 & 4.6 \\
\hline
\end{tabular}

\begin{tabular}{l|l}
3 & 2.8 \\
\hline
\end{tabular}

\begin{tabular}{l|l}
1 & 0.9 \\
\hline
\end{tabular}

\begin{tabular}{l|l}
1 & 0.9 \\
\hline
\end{tabular}

\begin{tabular}{l|l}
1 & 0.9 \\
\hline
\end{tabular}

\begin{tabular}{l|l}
1 & 0.9 \\
\hline 1 & 0.9
\end{tabular}

\begin{tabular}{l|l}
1 & 0.9 \\
\hline & 0.9
\end{tabular}

\begin{tabular}{l|l}
1 & 0,9 \\
\hline 3 & 2.8
\end{tabular}

\begin{tabular}{l|l}
3 & 2.8 \\
\hline 2 & 1.8 \\
\hline
\end{tabular}

\begin{tabular}{l|l}
66 & 62.9 \\
\hline
\end{tabular}

\begin{tabular}{l|l}
39 & 37.1 \\
\hline
\end{tabular}

\begin{tabular}{l|l}
\hline 33 & 31.4 \\
\hline 72 & 68.6
\end{tabular}

\begin{tabular}{l|l}
\hline & 68.6 \\
\hline 33 & 31.4 \\
\hline 72 & 68.6
\end{tabular}

\begin{tabular}{|c|c|c|}
\hline & $\mathrm{N}$ & $\%$ \\
\hline \multicolumn{3}{|l|}{ Sinus tract } \\
\hline Yes & 49 & 46.7 \\
\hline No & 56 & 53.3 \\
\hline \multicolumn{3}{|l|}{ Root canal length } \\
\hline Within $1 \mathrm{~mm}$ from the apex & 46 & 47.4 \\
\hline$>1 \mathrm{~mm}$ short of apex & 39 & 40.2 \\
\hline$>1 \mathrm{~mm}$ overfilled & 12 & 12.4 \\
\hline \multicolumn{3}{|l|}{ Homogenous filling } \\
\hline Yes & 45 & 45.0 \\
\hline No & 55 & 55.0 \\
\hline \multicolumn{3}{|c|}{ Separated instrument within root canal } \\
\hline $\mathrm{Da}$ & 3 & 2.9 \\
\hline $\mathrm{Ne}$ & 101 & 97.1 \\
\hline \multicolumn{3}{|l|}{ Intracanal post } \\
\hline \multicolumn{3}{|l|}{ Metal confection } \\
\hline Yes & 8 & 7.7 \\
\hline No & 96 & 92.3 \\
\hline \multicolumn{3}{|l|}{ Metal individual } \\
\hline Yes & 22 & 21.2 \\
\hline No & 82 & 78.8 \\
\hline \multicolumn{3}{|c|}{ Fiber reinforced composite resin } \\
\hline Yes & 3 & 2.9 \\
\hline No & 101 & 97.1 \\
\hline \multicolumn{3}{|l|}{ Post lengtth } \\
\hline$<5 \mathrm{~mm}$ in root canal & 13 & 43.3 \\
\hline$>5 \mathrm{~mm}$ in root canal & 17 & 56.7 \\
\hline \multicolumn{3}{|l|}{ Canal not found } \\
\hline Yes & 1 & 1.0 \\
\hline No & 102 & 99.0 \\
\hline \multicolumn{3}{|l|}{ Size of radiolucency } \\
\hline No radiolucency & 2 & 2.0 \\
\hline Radiolucency $<2 \mathrm{~mm}$ & 19 & 19.0 \\
\hline Radiolucency $2-5 \mathrm{~mm}$ & 47 & 47.0 \\
\hline Radiolucency $>5 \mathrm{~mm}$ & 27 & 27.0 \\
\hline Lateral radiolucency & 5 & 5.0 \\
\hline \multicolumn{3}{|l|}{ Perforation } \\
\hline Yes & 23 & 23.2 \\
\hline No & 76 & 76.8 \\
\hline \multicolumn{3}{|l|}{ Treatment decision } \\
\hline No treatment & 3 & 2.7 \\
\hline Orthograde retreatment & 6 & 5.4 \\
\hline Apicoectomy & 100 & 90.1 \\
\hline Extraction & 2 & 1.8 \\
\hline \multicolumn{3}{|l|}{ Intraoperative finding } \\
\hline \multicolumn{3}{|l|}{ Bone fenestration } \\
\hline Yes & 65 & 71.4 \\
\hline No & 26 & 28.6 \\
\hline \multicolumn{3}{|l|}{ Dehiscence } \\
\hline Yes & 28 & 31.8 \\
\hline No & 60 & 68.2 \\
\hline \multicolumn{3}{|l|}{ Vertical fracture } \\
\hline Yes & 0 & 0.0 \\
\hline No & 88 & 100.0 \\
\hline
\end{tabular}

\begin{tabular}{|l|l|}
\hline $\mathbf{N}$ & $\%$ \\
\hline
\end{tabular}


(5.4\%), not doing any procedure $(2.7 \%)$ and extraction $(1.8 \%)$ were less frequently selected. The majority of the examined teeth were upper incisors $(66 \%)$. Most of the teeth were prosthetically reconstructed $(62.9 \%)$ and more than half $(53.5 \%)$ were supplied with an intracanal post (Table 1 ).

Root canal filling was homogeneous and within $1 \mathrm{~mm}$ from the apex in $21.6 \%$ of cases, while in $78.4 \%$ of cases filling was unsatisfactory according to either length or homogeneity. Considering all the variables and the homogeneity of filling (homogeneous or non-homogeneous), a statistically significant difference was noted only with respect to the length of the root canal filling $\left(\mathrm{p}=0.023, \chi^{2}\right.$-test $)$.

Comparing all the variables with respect to the length of the root canal filling, statistically significant differences were found for the following: the number of previous treatments/ retreatments, attempted endodontic retreatment before endodontic surgery, homogeneous filling, spontaneous pain, the presence of intracanal posts (metal individual and composite) and the presence of bone dehiscence (Table 2).
\%), nijedan postupak (2,7 \%) i ekstrakcija (1,8 \%) bili su rjeđi. Većina uključenih zuba bili su maksilarni sjekutići (66\%). Većina je bila protetički rekonstruirana $(62,9 \%)$, a više od pola $(53,5 \%)$ imalo je intrakanalnu nadogradnju (tablica 1.).

Punjenje korijenskog kanala bilo je homogeno i unutar 1 mm od apeksa u $21,6 \%$ slučajeva, a u 78,4 \% slučajeva punjenje je bilo nezadovoljavajuće prema kriteriju homogenosti i/ili duljine punjenja. Analizom odnosa homogenosti punjenja (homogeno ili nehomogeno) i svih ostalih varijabli, statistički značajna povezanost ustanovljena je jedino za duljinu punjenja ( $\mathrm{p}=0,023, \chi^{2}$-test).

Uspoređujući sve varijable $s$ duljinom punjenja korijenskog kanala, statistički značajne razlike ustanovljene su za sljedeće varijable: broj prethodnih liječenja/revizija, pokušaj revizije prije endodontske kirurgije, homogenost punjenja, spontana bol, prisutnost intrakanalne nadogradnje (metalne individualne i kompozitne) i dehiscijencija kosti (tablica 2.).

Table 2 The variables that were significantly related to the length of the root canal filling were determined using $\times 2$-test. Tablica 2. Varijable značajno povezane s duljinom punjenja korijenskog kanala određene s pomoću X2-testa

\begin{tabular}{|c|c|c|c|c|c|c|c|c|c|}
\hline & & & \multicolumn{6}{|c|}{ Filling length } & \multirow{3}{*}{$\mathbf{p}^{1}$} \\
\hline & \multicolumn{2}{|c|}{ Total } & \multicolumn{2}{|c|}{ Within $1 \mathrm{~mm}$} & \multicolumn{2}{|c|}{ Less than $1 \mathrm{~mm}$} & \multicolumn{2}{|c|}{ Overfilled } & \\
\hline & $\mathrm{N}$ & $\%$ & $\mathbf{N}$ & $\%$ & $\mathrm{~N}$ & $\%$ & $\mathbf{N}$ & $\%$ & \\
\hline \multicolumn{10}{|c|}{ Number of previous treatments } \\
\hline 0 & 1 & 1.1 & 0 & 0.0 & 0 & 0.0 & 1 & 8.3 & 0.031 \\
\hline 1 & 62 & 66.7 & 30 & 71.4 & 28 & 71.8 & 4 & 33.3 & \\
\hline 2 & 27 & 29.0 & 10 & 23.8 & 10 & 25.6 & 7 & 58.3 & \\
\hline 3 & 3 & 3.2 & 2 & 4.8 & 1 & 2.6 & 0 & 0.0 & \\
\hline \multicolumn{10}{|c|}{ Was revision attempted before root-end resection } \\
\hline Yes & 20 & 21.1 & 8 & 18.2 & 6 & 15.4 & 6 & 50.0 & 0.030 \\
\hline No & 75 & 78.9 & 36 & 81.8 & 33 & 84.6 & 6 & 50.0 & \\
\hline \multicolumn{10}{|c|}{ Symptoms } \\
\hline \multicolumn{10}{|c|}{ Spontaneous pain } \\
\hline Yes & 50 & 51.5 & 29 & 63.0 & 18 & 46.2 & 3 & 25.0 & 0.043 \\
\hline No & 47 & 48.5 & 17 & 37.0 & 21 & 53.8 & 9 & 75.0 & \\
\hline \multicolumn{10}{|c|}{ Homogeneous filling } \\
\hline Yes & 42 & 43.8 & 21 & 46.7 & 12 & 30.8 & 9 & 75.0 & 0.023 \\
\hline No & 54 & 56.3 & 24 & 53.3 & 27 & 69.2 & 3 & 25.0 & \\
\hline \multicolumn{10}{|c|}{ Intracanal post } \\
\hline \multicolumn{10}{|c|}{ Metal individual } \\
\hline Yes & 21 & 22.1 & 8 & 18.2 & 13 & 33.3 & 0 & 0.0 & 0.036 \\
\hline No & 74 & 77.9 & 36 & 81.8 & 26 & 66.7 & 12 & 100.0 & \\
\hline
\end{tabular}

Fiber reinforced composite sticks

\begin{tabular}{l|c|c|c|c|c|c|c|c|c}
\hline Yes & 3 & 3.2 & 0 & 0.0 & 1 & 2.6 & 2 & 16.7 & 0.013 \\
\hline No & 92 & 96.8 & 44 & 100.0 & 38 & 97.4 & 10 & 83.3 & \\
\hline
\end{tabular}

Presence of bone dehiscence

\begin{tabular}{l|c|c|c|c|c|c|c|c|c}
\hline Yes & 25 & 32.1 & 17 & 47.2 & 8 & 24.2 & 0 & 0.0 & 0.011 \\
\hline No & 53 & 67.9 & 19 & 52.8 & 25 & 75.8 & 9 & 100.0 &
\end{tabular}

$\mathrm{p}=$ statistical relevance $(\mathrm{p}<0,05)$

\section{Discussion}

Endodontic surgery was the preferred procedure in $90 \%$ of the referred cases. The main hypothesis of the research was thus affirmed. Non-surgical retreatment was attempted in a

\section{Rasprava}

Endodontsko-kirurški zahvat bio je preferiran u $90 \%$ upućenih slučajeva. Zato je potvrđena glavna hipoteza istraživanja. Nekirurška revizija pokušala se učiniti u razmjerno 
relatively low percentage of the referred cases (20.6\%), even though root canal fillings were unsatisfactory in most of them.

Residual infection due to inadequate cleaning and disinfection of the root canal space, or secondary infection due to inadequate obturation/sealing may lead to endodontic treatment failure (20). Intra-radicular microflora is polymicrobial, predominantly anaerobic and resembles to that of an untreated necrotic pulp (21). Therefore, in cases where an orthograde approach is possible, endodontic retreatment should be the treatment of choice. It was reported that the healing of periapical lesions after endodontic retreatment occurs in $74-98 \%$ of the cases, while the success rate of endodontic surgery, without previous retreatment, was significantly lower $(13,12,20)$. Furthermore, research by Torabinejad et al. (22) showed that the success of orthograde treatment lasted longer. Previous studies also report significant percentage of cases in which endodontic surgery was conducted, although according to the scientifically grounded criteria, orthograde retreatment should have been the treatment of choice (18, 23). It was concluded in previous studies that general dental practitioners do not appreciate endodontic retreatment as a treatment option, and the inclusion of a specialist of endodontics in the decision-making process on endodontic surgery was suggested $(18,23,24)$. Moreover, in almost $3 \%$ of the cases endodontics was not performed and in more than $65 \%$ of cases endodontic treatment was conducted only once, less than 3\% performed by a specialist of endodontics.

Oral surgery specialization bias in decision making was the subject of some previous studies where the referred patients were reassessed and based on audit criteria the authors reported that the endodontic surgery had not been indicated in considerable number of the patients $(18,23,25)$. Abramowitz et al. (18) came to conclusion that the percentage of "unnecessary"resections" was 55\%. Anyway, it is important to point out that the concept of endodontic surgery implies root-end resection with retrograde cavity filling, and that omitting the retrograde filling should negatively affect the outcome of the surgery. Since the purpose of our research was not to define the percentage of "unnecessary" endodontic surgeries, we are unable to give such assessments for our sample. However, we can conclude that certain number of cases could have been treated more conservatively, by an orthograde retreatment approach, especially considering intraradicular infection remaining after endodontic surgery in cases that had not been orthogradely retreated before. Nevertheless, it would be interesting to follow up the cases referred to oral surgery that had been treated surgically and those that had been forwarded to an endodontics specialist for orthograde retreatment. At this point there is no systematic follow up of patients reffered to Oral surgery and Endodontics at the School of Dental Medicine, and majority of patients are followed by their primary dentist. It was therefore at this point difficult to obtain the data necessary for the assesment of the sucess rates of surgical and conservative treatments, and asses the percentage of unnecesary surgeries. We can however notice that in the von Arx et al.(25) study, the percentage of teeth in which an oral surgery specialist decided for root-end resection was significantly lower $(59.1 \%)$ malom postotku (20,6\%), premda punjenja korijenskih kanala uglavnom nisu zadovoljavala.

Rezidualna infekcija zbog neadekvatnog čišćenja i dezinfekcije korijenskog kanala ili sekundarne infekcije zbog neadekvatne opturacije mogu rezultirati neuspjehom endodontskog liječenja (20). Intraradikularna mikroflora je polimikrobna i prevladavajuće anaerobna te je nalik na onu u netretiranoj nekrotičnoj pulpi (21). Zato bi u slučaju kada je moguć ortogradni pristup, revizija endodontskog liječenja trebala biti postupak izbora. Podatci iz literature pokazuju da se cijeljenje periapikalnih lezija nakon revizije liječenja događa u 74 do $98 \%$ slučajeva, a značajno je manji postotak uspješnosti endodontske kirurgije, bez prethodne revizije $(13,12,20)$. Nadalje, istraživanje Torabinejada i suradnika (22) pokazalo je da je uspjeh nakon ortogradne revizije dugotrajniji. Ranija istraživanja također govore o značajnom postotku slučajeva za koje je provedena endodontska kirurgija, a prema znanstveno utemeljenim kriterijima postupak izbora trebala je biti ortogradna revizija $(18,23)$. U ranijim istraživanjima zaključeno je da primarni stomatolozi ne cijene endodontsku reviziju kao terapijsku mogućnost te je predloženo uključivanje specijalista endodoncije u proces odlučivanja o provedbi endodontsko-kirurškog zahvata $(18,23,24)$. Nadalje, u gotovo $3 \%$ slučajeva endodoncija nije nikad provedena, u $65 \%$ slučajeva endodontski je tretman obavljen samo jedanput, a u manje od $3 \%$ liječio ju je specijalist endodoncije.

Utjecaj specijalizacije iz oralne kirurgije na odluku o postupku, bio je tema nekoliko ranijih istraživanja u kojima se upućene pacijente ponovno procjenjivalo prema revidiranim kriterijima pa su autori naveli da endodontsko-kirurški zahvat nije bio indiciran u velikom broju slučajeva $(18,23,25)$. Abramovitz i suradnici(18) zaključili su da je postotak nepotrebnih resekcija $55 \%$. Ipak, važno je istaknuti da koncept oralne kirurgije obuhvaća resekciju vrška korijena s retrogradnim punjenjem, a izostavljanje retrogradnog punjenja negativno utječe na ishod operativnog zahvata. Budući da svrha ovog istraživanja nije bila utvrditi postotak nepotrebnih kirurških zahvata, nismo u stanju dati takvu procjenu za naš uzorak. No možemo zaključiti da je određeni broj slučajeva mogao biti tretiran konzervativnije, posebno ako se uzme u obzir intraradikularna infekcija koja ostaje u kanalu nakon endodontsko-kirurškoga zahvata u slučaju da prije nije učinjena revizija. Ipak, bilo bi zanimljivo pratiti slučajeve upućene na oralnu kirurgiju koji su kirurški tretirani i one proslijeđene specijalistu endodoncije zbog ortogradne revizije liječenja. Trenutačno ne postoji sustavno praćenje pacijenata upućenih i obrađenih u Zavodu za oralnu kirurgiju i Zavodu za endodonciju te je većinu pratio njihov primarni stomatolog. Zato je zasad teško doći do podataka na temelju kojih bi se odredio postotak uspješnosti kirurškog i konzervativnog tretmana te postotak nepotrebnih operacija. Možemo ipak istaknuti da je u istraživanju von Arxa i suradnika (25) postotak zuba za koje se specijalist oralne kirurgije odlučio za resekciju bio značajno niži $(59,1 \%)$, negoli u našem istraživanju (90 \%). To može biti zbog toga što se naš uzorak većinom sastojao od pacijenata s već dogovorenim operacijama.

Radiološki procijenjena kvaliteta punjenja korijenskih 
than in our study (90\%). The reason for this difference is that our sample consisted mostly of patients with an already scheduled surgery.

Radiographically estimated quality of root canal fillings done by general practitioners in Sweden was satisfactory in only $31 \%$ of the cases and after a course in machine endodontics, the quality was significantly improved and was satisfactory in $51 \%$ of the cases (26). Similarly, in our research, $45 \%$ of fillings were estimated as homogeneous (Table 1). The Swedish authors reported that the homogeneity and filling length had no influence on the size of the periapical lesion, also similar to our results.

When it comes to symptoms before operation, we found significant connection between the filling length and spontaneous pain $(p<0.05)$. It is interesting that spontaneous pain and alveolar bone loss (presence of dehiscence) were more commonly recorded when the filling was the satisfactory in length $(\mathrm{p}<0.05)$, i.e. within $1 \mathrm{~mm}$ from the apex.

In our research $21.6 \%$ of the cases with adequate fillings had symptoms or did not show signs of healing. The reason for that can be intraradicular infection with microorganisms resistant to intracanal medicaments and irrigants, which lead to failure after lege artis endodontic treatment $(7,27)$. Additionally, the elimination of infection from the apical part of the canal and consequent failure might be caused by procedural mistakes done during primary endodontic treatment, that are not necessarily radiographically detectable, e.g. transposition and transportation of apex $(20,28)$. The decision about the treatment should therefore not be based solely on the radiographic finding (17). In our research, the connection between the treatment decision and radiographically estimated quality of filling was not significant $(\mathrm{p}<0.05)$. Although the diagnostic value of panoramic radiographs is inferior (29), the panoramic radiographs were in our study included in the analysis. The reason for including them is their low number (only 2 ), and their reported sufficient diagnostic value in diagnosing apical periodontoitis (30).

In addition to intraradicular infection, the cause of failure of endodontic treatment can be an extraradicular infection in the form of periradicular actinomycosis, foreign body reaction or true cyst $(7,9)$. In these cases, healing and/or withdrawal of symptoms after endodontic retreatment cannot be expected, and surgical approach is indicated: root-end resection and the removal of foreign body or excochleation of the radicular cyst (9). However, these treatment failure causes are relatively rare, and intraradicular microbial infection in the apical part of root canal remains the most common cause of endodontic treatment failure $(7,10)$.

Almost $63 \%$ of the cases in our study were prosthetically reconstructed and more than $30 \%$ had intracanal post. This made orthograde approach to root canal difficult, and presumably this was the main reason these patients were referred to endodontic surgery, although, according to the criteria of radiographic appearance of the fillings, orthograde retreatment should have been the first choice. In the context of the rationalization we realize that endodontic surgery seems like a favourable choice in such cases, because prosthetic work is preserved. Within our sample, $50 \%$ of the referred crowned kanala koje su liječili primarni stomatolozi u Švedskoj bila je zadovoljavajuća u samo $31 \%$ slučajeva, a nakon tečaja o strojnoj endodonciji kvaliteta punjenja značajno se popravila te je zadovoljavala u $51 \%$ slučajeva (26). Slično tomu, u našem je istraživanju $45 \%$ punjenja bilo procijenjeno kao homogeno (tablica 1.). Švedski su autori također naveli da homogenost i duljina punjenja nisu bile u korelaciji s veličinom periapikalne lezije, što je bio slučaj i u našem istraživanju. Kad su u pitanju simptomi prije operacije, našli smo značajnu povezanost između duljine punjenja i spontane boli $(\mathrm{p}<$ $0,05)$. Zanimljivo je da su spontana bol i gubitak alveolarne kosti (dehiscijencija) bili češći kada je punjenje bilo zadovoljavajuće duljine $(\mathrm{p}<0,05)$, i. e. unutar $1 \mathrm{~mm}$ od apeksa.

$U$ našem je istraživanju $21,6 \%$ slučajeva $s$ adekvatnim punjenjem imalo simptome ili nije pokazivalo znakove cijeljenja. Uzrok može biti intraradikularna infekcija mikroorganizmima rezistentnih na intrakanalne lijekove $\mathrm{i}$ iriganse, što obično završava neuspjehom nakon endodontskog postupka lege artis $(7,27)$. Nadalje, zaostala infekcija u apikalnom dijelu kanala i posljedični neuspjeh, mogu biti uzrokovani proceduralnim pogreškama tijekom primarnog endodontskog liječenja koje nisu nužno detektibilne na radiogramu, to su, na primjer, transpozicija i transportacija apeksa $(20,28)$. Odluka o postupku zato se ne bi trebala temeljiti samo na radiološkom nalazu (17). U našem istraživanju nije bilo značajne povezanosti između odluke o postupku i radiološki procijenjene kvalitete punjenja $(\mathrm{p}<0,05)$. Premda je dijagnostička vrijednost ortopantomograma slabija (29), oni su u našoj studiji uključeni u analizu. Razlog za to bio je njihov mali broj (samo 2 ) i njihova, prema literaturi, dostatna dijagnostička vrijednost u dijagnozi apikalnog parodontitisa (30).

Uz intraradikularnu infekciju, uzrok za neuspjeh endodontske terapije može biti ekstraradikularna infekcija u obliku periradikularne aktinomikoze, reakcije stranog tijela i pravih cista $(7,9)$. U tim slučajevima cijeljenje i/ili povlačenje simptoma nakon revizije liječenja ne može se očekivati te je indiciran kirurški pristup - resekcija vrška korijena i uklanjanje stranog tijela ili ekskohleacija radikularne ciste (9). No ti uzroci neuspjeha razmjerno su rijetki, pa intraradikularna mikrobna infekcija u apikalnom dijelu ostaje najčešći uzrok za neuspjeh endodontske terapije $(7,10)$.

Čak je $63 \%$ slučajeva u našoj studiji bilo protetički rekonstruirano, a više od $30 \%$ imalo je intrakanalnu nadogradnju. To je otežalo ortogradni pristup liječenju korijenskog kanala te je to vjerojatno bio glavni razlog za upućivanje pacijenata na endodontsku kirurgiju, premda je prema kriterijima radiološkog izgleda punjenja, ortogradna revizija trebala biti prvi izbor. U kontekstu racionalizacije, izbor endodontske kirurgije čini se dobrim jer je sačuvan protetički rad. U našem uzorku $50 \%$ okrunjenih zuba bili su nosači mosta. Ipak, ortogradna revizija prije kirurškog postupka značajno povećava izglede za uspjeh endodontskog kirurškog zahvata (20). Čak ni intrakanalne nadogradnje ne bi trebale biti izravan kriterij za isključivanje revizije kao terapijskog postupka $(20,23)$. Uz to, velik broj nadogradnji u našem istraživanju bio je kraći od $5 \mathrm{~mm}$, što je također jedan od kriterija koji zub čini potencijalnim kandidatom za ortogradnu reviziju (23). 
teeth were bridge carriers. Nevertheless, orthograde retreatment of the root canal filling before surgical procedure significantly increases the chances of success of endodontic surgery (20). Even the presence of intracanal posts should not mean immediate exclusion of retreatment as a therapeutic procedure of choice $(20,23)$. Additionally, great number of posts in our sample was shorter than $5 \mathrm{~mm}$ which is also one of the criteria that makes a tooth a potential candidate for orthograde retreatment (23).

\section{Conclusions}

Endodontic surgery was a procedure of choice for most patients referred by a general practitioner to an oral surgery specialist. Considering that the percentage of radiographically assessed teeth with unsatisfactory root canal fillings was high, and the percentage of teeth in which orthograde retreatment was attempted prior to the referral to oral surgery specialist was low, we can conclude that the awareness about the possibilities of successful treatment by non-surgical approach is insufficient.

\section{Acknowledgements}

The authors deny any conflicts of interest.

The results of this reserach have been presented in the form of poster presentation at the international conference "Science and clinical work synergy", Zagreb 2017.

The research presented here was supported by the University of Zagreb, grant "Comparative evaluation of rotational and reciprocal endoodntics", 2017.

\section{Conflict of interest}

The authors report no conflict of interest.

\section{Zaključak}

Endodontska kirurgija bila je postupak izbora za većinu pacijenata koje je primarni stomatolog uputio oralnom kirurgu. Uzimajući u obzir da je postotak zuba s radiološki utvrđenim neadekvatnim punjenjem bio visok, a postotak onih na kojima se pokušala učiniti revizija prije upućivanja na kirurgiju mali, zaključujemo da znanje o mogućnostima uspješnog nekirurškog liječenja nije dovoljno.

\section{Zahvala}

Rezultati ovog istraživanja prezentirani su u Zagrebu 2017. u obliku postera na međunarodnom kongresu Sinergija znanosti i kliničkoga rada.

Istraživanje je obavljeno u sklopu potpore Sveučilišta u Zagrebu Komparativna evaluacija rotirajuće i recipročne strojne endodontske tehnike - klinička studija (voditeljica prof. dr. sc. Goranka Prpić Mehičić - 2017.).

\section{Sukob interesa}

Autori nisu bili u sukobu interesa.

\section{Sažetak}

Svrha: Svrha istraživanja bila je radiološki procijeniti kvalitetu punjenja korijenskih kanala pacijentima upućenima na endodontski kirurški zahvat te korelirati nalaz s odlukom o terapiji. Također su se željeli analizirati klinički simptomi i veličina periapikalne lezije na radiogramu i povezati ih s odlukom o terapijskom postupku, uključujući nekiruršku reviziju liječenja, endodontsku kirurgiju i ekstrakciju. Materijali i postupci: Sastavljen je upitnik za prikupljanje podataka. U istraživanju je sudjelovalo 86 pacijenata (sa 109 zuba) upućenih na endodontski kirurški zahvat. Kvaliteta punjenja korijenskih kanala procijenjena je prema homogenosti i duljini punjenja na digitalnim radiogramima. Podatci su analizirani X2-testom i t-testom. Rezultati: Od zuba kojima je bio potreban endodontski kirurški zahvat, $97,2 \%$ prije je liječio primarni liječnik dentalne medicine, endodontska revizija punjenja primijenjena je u 20,6\% slučajeva, a punjenje korijenskog kanala bilo je homogeno i unutar $1 \mathrm{~mm}$ od apeksa u 21,6\% slučajeva. Endodontska kirurgija, revizija, ekstrakcija ili nijedan postupak, odabrani su redom u 90,1 \%, 5,4 \%, 1,8 \% i 2,7 \% slučajeva. Zaključak: Nizak postotak adekvatnih punjenja korijenskog kanala i visok postotak kad je riječ o odlukama za endodontski kirurški postupak, sugeriraju da postoji potreba za povećanjem svijesti o mogućoj nekirurškoj reviziji endodontskog liječenja.
Zaprimljen: 27. prosinca 2018. Prihvaćen: 6. svibnja 2019.

Adresa za dopisivanje Ana Ivanišević Malčić Sveučilište u Zagrebu, Stomatološki fakultet Gundulićeva 5, 10000 Zagreb, Hrvatska tel: +385989872905 faks: +38514802159 aivanisevic@sfzg.hr

Ključne riječi odluka o terapijskom postupku, dentalna radiografija, endodoncija, endodontska kirurgija, revizija liječenja

\section{References}

1. European Society of Endodontology. Quality guidelines for endodontic treatment: consensus report of the European Society of Endodontology. Int Endod J. 2006;39(12):921-930.

2. MeSH Browser [database on the Internet]. American Association of Endodontists. Guide to clinical endodontics. 6th ed. [Internet]. Chicago, IL: American Association of Endodontists; c2016 [cited 2017 Sept 15]. Available from:http://www.nxtbook.com/nxtbooks/aae/guidetoclinicalendodontics6/index.php\#/1.
3. Chugal NM, Clive JM, Spångberg LS. A prognostic model for assessment of the outcome of endodontic treatment: effect of biologic and diagnostic variables. Oral Surg Oral Med Oral Pathol Oral Radiol Endod. 2001 Mar;91(3):342-52.

4. MeSH Browser [database on the Internet]. American Association of Endodontists, Special Committee. Glossary of endodontic terms. 9th ed. [Internet]. Chicago, IL: American Association of Endodontists; c2016 [cited 2017 Sept 15]. Available from: http:// 
www.nxtbook.com/nxtbooks/aae/endodonticglossary2016/index.php\#/1.

5. Ng YL, Mann V, Rahbaran S, Lewsey J, Gulabivala K. Outcome of primary root canal treatment: systematic review of the literature - part 1. Effects of study characteristics on probability of success. Int Endod J. 2007 Dec;40(12):921-39.

6. Peikoff MD. Treatment planning dilemmas resulting from failed root canal cases. Aust Endod J. 2005 Apr;31(1):15-20.

7. Nair PNR. Endodontic failures: the pathobiology of posttreatment apical periodontitis. In: Cohen S, Hargreaves KM, editors. Pathways of the Pulp. 9th ed. St Louis: Mosby Elsevier; 2006. p. 918-943.

8. Chandra A. Discuss the factors that affect the outcome of endodontic treatment. Aust Endod J. 2009 Aug;35(2):98-107.

9. Ricucci D, Siqueira JF Jr. Failure of the endodontic treatment. In: Ricucci D, Siqueira JF Jr, editors. Endodontology: an integrated biological and clinical view. London: Quintessence Publishing; 2013. p. 315-365.

10. Lin LM, Rosenberg PA, Lin J. Do procedural errors cause endodontic treatment failure? J Am Dent Assoc. 2005 Feb;136(2):187-93; quiz 231.

11. Evans GE, Bishop K, Renton T-editors. Guidelines for surgical endodontics. 2nd ed. London: The Royal College of Surgeons of England; 2012.

12. Cohn SA. Treatment choices for negative outcomes with non-surgical root canal treatment: non-surgical retreatment vs. surgical retreatment vs. Implants. Endod Top. 2005; 11: 4-24. NIJE U PUBMEDU

13. Ng YL, Mann V, Gulabivala K. A prospective study of the factors affecting outcomes of nonsurgical root canal treatment: part 1: periapical health. Int Endod J. 2011;44(7):583-609.

14. Taschieri S, Corbella S, Del Fabbro M. Do gingival soft tissues benefit from the application of a papilla preservation flap technique in endodontic surgery? J Oral Maxillofac Surg. 2014 Oct;72(10):1898-908.

15. Yun HJ, Jeong JS, Pang NS, Kwon IK, Jung BY. Radiographic assessment of clinical root-crown ratios of permanent teeth in a healthy Korean population, J Adv Prosthodont. 2014;6(3):171-176.

16. Messer HH. Clinical judgement and decision making in endodontics. Aust Endod J. 1999 Dec;25(3):124-32.

17. Matijević J, Čizmeković Dadić T, Prpić Mehičić G, Anić I, Šlaj M, Jukić Krmek S. Prevalence of apical periodontitis and quality of root canal fillings in population of Zagreb, Croatia: a cross-sectional study. Croat Med J. 2011 Dec 15;52(6):679-87.
18. Abramovitz I, Better H, Shacham A, Shlomi B, Metzger Z. Case selection for apical surgery: a retrospective evaluation of associated factors and rational. J Endod. 2002 Jul;28(7):527-30.

19. Eleftheriadis G I, Lambrianidis T P. Technical quality of root canal treatment and detection of iatrogenic errors in an undergraduate dental clinic. Int Endod J. 2005;38(10):725-734.

20. Roda RS, Gettleman BH. Nonsurgical retreatment. In Cohen S, Hargreaves KM, editors. Pathways of the pulp. 9th ed. ST Louis: Mosby Elsevier; 2006. p. 994-1010.

21. Sundqvist G. Ecology of the root canal flora. J Endod. 1992 Sep;18(9):427-30.

22. Torabinejad M, Corr R, Handysides R, Shabahang S. Outcomes of nonsurgical retreatment and endodontic surgery: a systematic review. J Endod. 2009;35(7):930-937.

23. Beckett $\mathrm{H}$. Impact of a restorative dentistry service on the prescription of apical surgery in a district general hospital. Ann R Coll Surg Engl. 1996;78(4):369-371.

24. Çiçek E, Özsezer-Demiryürek E, Özerol-Keskin N B, Murat N. Comparison of treatment choices among endodontists, postgraduate students, undergraduate students and general dentists for endodontically treated teeth. Int Dent J. 2016 Aug;66(4):201-7.

25. von Arx T, Roux E, Bürgin W. Treatment decisions in 330 cases referred for apical surgery. J Endod. 2014 Feb;40(2):187-91.

26. Koch M, Wolf E, Tegelberg A, Petersson K. Effect of education intervention on the quality and long-term outcomes of root canal treatment in general practice. Int Endod J. 2015 Jul;48(7):680-9.

27. Toljan I, Bago Jurič I, Anić I. Eradication of Intracanal Enterococcus Faecalis Biofilm by Passive Ultrasonic Irrigation and RinsEndo System. Acta Stomatol Croat. 2016;50(1):14-22.

28. Lopes DS, Pessoa MA, Aguiar CM. Assessment of the Centralization of Root Canal Preparation with Rotary Systems. Acta Stomatol Croat. 2016;50(3):242-250.

29. Mishra I, Karjodkar FR, Sansare K, Dora AC, Tambawala SS, Kapoor R, Sharma SR. Diagnostic Value of Extraoral Periapical Radiograph in Comparison to Intraoral Periapical Radiograph: A Cross-sectional, Institutional Study. Contemp Clin Dent. 2018 JulSep;9(3):406-409.

30. Nardi C, Calistri L, Grazzini G, Desideri I, Lorini C, Occhipinti M, Mungai F, Colagrande S. Is Panoramic Radiography an ACcurate Imaging Technique for the Detection of Endodontically Treated Asymptomatic Apical Periodontitis? J Endod. 2018 Oct;44(10):1500-1508. 